\title{
Una lectura deconstructiva del régimen carnofalogocéntrico. Hacia una ética animal de la diferencia
}

\author{
A deconstructive reading of the \\ carno-phallogocentric regime. \\ Towards an animal ethics of difference
}

\begin{abstract}
Resumen: En el contexto del debate contemporáneo en torno a la cuestión animal, las filosofías deconstructivas de la subjetividad ofrecen un camino para pensar conceptos que inauguren un pensamiento ético y político de la animalidad. Dado que señalan un camino abierto y diseminado, permiten pensar la cuestión animal desde una perspectiva crítica e históricamente situada. El presente artículo comienza con algunas consideraciones en torno a las relaciones de poder/saber entre humanos y animales, para así proponer ciertas notas que indaguen, a partir de una lectura crítica del régimen carnofalogocéntrico, las posibilidades ético-políticas derivadas de la deconstrucción de la dicotomía humano/animal.

Palabras claves: animalidad, Derrida, subjetividad, carnofalogocentrismo, ética de la diferencia, comunidad.
\end{abstract}

ANAHÍ GONZÁLEZ

\begin{abstract}
In the context of the contemporary debate around the "question of the animal", the deconstructive philosophies of subjectivity offer a path to think concepts that inaugurate an ethical and political thinking of animality. They allow thinking about the question of the animal from a critical and historically situated perspective, since they show an open and disseminated path. This article begins with some considerations about the power/knowledge relations between humans and animals in order to propose certain notes that inquire the ethical-political possibilities arising from the deconstruction of the human/animal dichotomy from a critical reading of the carnophallogocentric regime.
\end{abstract}

Keywords: animality, Derrida, subjectivity, carno-phallogocentrism, ethics of difference, community.

Fecha de recepción: 06/03/2015. Fecha de aceptación: 02/08/2015.

* Licenciada en Filosofía por la Facultad de Filosofía, Humanidades y Artes de la Universidad Nacional de San Juan (Argentina), distinguida con Mención de Honor y Medalla de Plata. Doctoranda en Filosofía por un convenio de cotutela entre la Universidad Nacional de San Martín (Argentina) y la Universidad de Paris VIII (Francia). Becaria del Consejo Nacional de Investigaciones Científicas y Técnicas (CONICET). Es miembro del Institute for Critical Animal Studies (nodo latinoamericano) y del Proyecto de Investigación Declinaciones de la biopolítica: nuevos modos de subjetivación, dirigido por la Dra. Beatriz Podestá. Participa regularmente en congresos y publicaciones referidas a la cuestión de la animalidad en el pensamiento de Jacques Derrida. Co-directora de la Revista latinoamericana de estudios críticos animales. Correo electrónico: gonzalezgabriela@outlook.com 
La pregunta por el animal en el pensamiento occidental contemporáneo emerge como un conjunto abierto de indagaciones sobre las estructuras y dispositivos de poder que sostienen la explotación, sujeción y subordinación de los animales y de los seres históricamente sub-humanizados. Particularmente, en el terreno de la filosofía posthumanista, los trabajos de Cary Wolfe (2003), Matthew Calarco (2008), Rosi Braidotti (2005), entre otros, han contribuido a desentrañar los modos en que lo humano se ha definido por la exclusión y el sacrificio de los clasificados como animales. En este sentido, el problema de la dicotomía humano/animal deviene una categoría clave no sólo para desmantelar el discurso de la metafísica de la presencia, sino también como un problema político en relación a los modos en que se "produce" la comunidad a partir de la gestión biopolítica de los cuerpos humanos y no-humanos. En esta configuración, existe un esfuerzo teórico que asume la tarea de pensar el lugar de los animales en el mundo y el tipo de relación que tenemos con ellos, es decir, "cuáles son nuestras maneras de amar, de usar, de estudiar o de matar a los animales, en definitiva, de vivir con ellos" (Balibar \& Hoquet, 2009: 645). Desbaratar esa dicotomía es entonces un desafío insoslayable para el pensar actual, puesto que allí se condensa una política (y una ontología) eugenésica, racista, patriarcal, heterosexual, colonial y antropocéntrica que perpetúa una sangrienta tarea de exclusión y sacrificio de otros "humanos".

Si bien autores como Tom Regan (1983), Peter Singer (1995) o Gary Francione (1996), han cuestionado el proceso de explotación y de sojuzgamiento al que son sometidos los animales en nuestra coexistencia política actual, el protagonista de sus enfoques éticos es el hombre varón, racional, libre, representativo, autónomo y propietario que nos legó la modernidad. A partir de ese presupuesto, la relación con el otro animal es mentada bajo una lógica de homogeneización que los piensa como un otro-igual, deviniendo un planteo unificador y totalizante. En otras palabras, sus planteos éticos-políticos son construidos con un alcance universal sobre la hipótesis metafísica del Sujeto que justamente ha requerido de unos Otros (sacrificables) para su afirmación: los cuerpos racializados, empobrecidos, disidentes sexuales, enfermos, mujeres, $y$, por supuesto, animales.

En cambio, las filosofías deconstructivas de la subjetividad ofrecen un camino diferente para pensar otros conceptos que inauguren un pensamiento ético y político de la animalidad. Particularmente, la cuestión del animal ha sido tratada por Jacques Derrida en numerosas oportunidades a lo largo de su obra. De modo tal que el problema de lo viviente y del ser vivo animal se encuentra en el corazón de un pensamiento dedicado a "hacer temblar" las estructuras clásicas de la política contemporánea. Si la vida se ha presentado desde siempre para el pensamiento occidental a través de dicotomías jerárquicas, las reflexiones de Derrida posibilitan pensar elementos para la emergencia de otros modos posibles de convivencia entre vivientes. En este sentido, el presente trabajo ofrece algunas notas que exploran las posibilidades ético-políticas que derivan de la deconstrucción del régimen carnofalogocéntrico, a fin de visualizar nuevos lazos en una comunidad de singularidades humanas y animales.

\section{Políticas del sacrificio animal}

La configuración carnofalogocéntrica de la metafísica occidental se basa en un sistema axiológico que distribuye a los vivientes en una escala jerárquica que va de lo considerado 
como verdaderamente humano a lo no-humano. Ello implica no sólo la exclusión de los animales del ámbito comunitario sino también la marginación de las mujeres, los disidentes sexuales, las personas racializadas, los niños y diversas corporalidades disidentes, que son consideradas "menos humanas" en relación al ideal hegemónico del Sujeto moderno/ colonial (idealmente hombre, blanco, heterosexual, racional y burgués). Este se caracteriza por erigirse como el objetivo lugar de la universalidad desde el cual puede, soberanamente, disponer de la vida y de la muerte de aquello que sitúa en el horizonte de la animalidad. En otros términos, el sujeto soberano se define oposicionalmente y se determina jerárquicamente en contraste con del modo de ser de lo que nombra como "animal".

Derrida ha insistido en la deconstrucción de ese límite absoluto y sin fisuras establecido, con todo rigor, entre el Hombre y el Animal. Tal deconstrucción cuestiona la pretendida pureza sin contaminación del hombre, en la que justamente él fundamenta su capacidad de sometimiento. Siguiendo la genealogía que el filósofo traza en L'animal que donc je suis, es posible mostrar que el término "animal" opera, en la tradición occidental, como función de corte pretendiendo garantizar la distinción entre lo humano y lo inhumano conforme a un pensamiento dualista e identitario: mientras se considera que el hombre posee pensamiento, lenguaje, conciencia y responde; el animal, al ser considerado puro automatismo sin capacidad de respuesta, queda exceptuado incondicionalmente de la esfera ético-política. Ese gesto, que mina completamente las diferencias entre cada animal, así como la posibilidad de pensar cada uno en su singularidad, no es inocuo frente a las relaciones de dominación, sujeción o explotación que se establecen entre humanos y animales. El sometimiento sistemático e industrializado de estos últimos como bienes económicos y de propiedad privada, se sostiene sobre dicha dualidad ontológica que establece su legitimidad política.

El logocentrismo antropocéntrico, al pensar al animal como carente de respuesta, lo exhibe como espectáculo teórico: el animal mirado y no el animal que nos mira (Derrida, 2008). Este animal, en cuanto cosa observada, aparece como el objeto de un hombre que lo ubica en el lugar de la disponibilidad, sometido al saber-poder humano, ejerciendo sobre él lo que Derrida llama "violencia soberana". Dicha operación de saber entraña un ejercicio de soberanía que, en su mirada dirigida hacia un objeto visible, dispone de él. El filósofo ilustra ese dispositivo de saber-poder soberano, dirigido a la curiosidad, tanto en su avidez de saber, como en su seducción por el espectáculo, con la escena científica en la cual Luis XIV asiste, en su ménagerie de Versalles, a la autopsia de un elefante (Derrida, 2010, 330331). La figura del Rey Sol está presente frente al elefante mientras éste se encuentra en la mesa de vivisección convertido en un "cadáver" a disponibilidad de la mirada, del poder, del tener del saber humanos. La escena del rey frente al "animal" es un cuadro político porque "hace representación" de las políticas de sacrificio de lo viviente; es decir, coloca en escena, a través de un suceso perteneciente al Rey Sol, lo que ha sido su soberanía: una contante "erección" por encima de todo lo vivo ejerciendo su autoridad como soberano. A propósito de esta escena, señala Derrida:

El saber teórico es, al menos en la figura dominante, un ver, un theôrein teatral, una mirada puesta sobre un objeto visible, una experiencia ante todo óptica que apunta a tocar con los ojos lo que está a mano, a punta de escalpelo, y este modelo óptico 
puede ser una autopsia soberana, como en el caso del gran elefante al que se le hizo la autopsia y fue observado, inspeccionado, disecado ante la mirada de Luis XIV durante la ceremonia o la lección de anatomía de 1681. (Derrida, 2010, 329).

Si bien la Casa de Fieras de Luis XIV dejó de existir al desaparecer la monarquía, el lugar "demócrata-popular" que la caída de la monarquía francesa trae para el animal es el zoológico. Se trata de "una casa de fieras demócrata-popular, laica y republicana, conforme a la nueva soberanía" (2010: 378-379), en la que la observación de los animales resulta útil a la historia natural, la fisiología y la economía. Mientras la Casa de Fieras constituía un espacio de acumulación de animales exóticos, de representación y de escenificación de la vida al que sólo podían concurrir el Rey y la corte; la nueva institución, el zoológico, constituye un espacio democrático al que pueden asistir todos. Derrida señala cómo, a pesar de que se transforme la soberanía del Rey Luis XIV y se transite luego de la Revolución Francesa a la República, la soberanía sigue siendo el mismo ejercicio falocrático que caracterizaba al Rey como soberano. El zoológico es, entonces, un lugar en el que los animales se encuentran sometidos a la ver-saber-poder-tener del sujeto humano.

Al explicar la relación entre metafísica y violencia, Derrida denuncia la "vieja amistad oculta entre la luz y el poder, vieja complicidad entre la objetividad teórica y la posesión técnico-político" (2003, 145-146). Es decir, el establecimiento de una objetividad teórica supone una operación política que justifica la "necesaria" sujeción y organización de la vida. Es, en rigor, una de las maneras más eficientes de excluir a los márgenes del olvido a aquellos que perturban los discursos que se presentan de modo absoluto y universal. En este sentido, la mencionada escena científica re/produce la lógica de la disponibilidad del animal por parte del Hombre, legitimando su ejercicio. El paquidermo ante la mirada de Luis XIV constituye una escena sacrificial en la cual la "carne" está al servicio del estudio científico y del espectáculo.

Una "economía" (oiko-nomia) atraviesa estas instituciones: tanto los circos como los zoológicos están regidos por un saber-hacer que consiste en proporcionar una casa, un hábitat para los vivientes en procedimientos que oscilan entre la domesticación (la adecuación a las leyes de la casa familiar) la doma, el amaestramiento, la cría, entre otras modalidades de apropiación de la vida, del poder ser señor y soberano (mediante la captura, la caza, la cría, el comercio, el encierro), en los que la economía es "la condición general de esta ipseidad como dominio soberano sobre la bestia, en esta única y misma experiencia que encadena, con la bestia, el poder, el saber, el ver y el tener" (Derrida, 2010, 334).

Según Derrida desde hace aproximadamente dos siglos las relaciones entre los llamados humanos y animales han experimentado una transformación que se acelera a un ritmo incalculable. Más allá de la caza, la pesca, la domesticación o la explotación tradicional de la energía animal (transporte, labranza, etc.), los desarrollos conjuntos de saberes zoológicos, etológicos y genéticos, junto con determinadas técnicas de intervención, han aumentado descomunalmente la cría y explotación orientada a la producción de carne, medicamentos, etcétera. La inseminación artificial a gran escala, la cría selectiva, la clonación, los cruces genéticos y la manipulación hormonal son algunos de los métodos en la administración biopolítica de las poblaciones animales en la industria de la alimentación. Se trata de "producción de vida" (que es, a un mismo tiempo, "producción de muerte") sólo para la 
disponibilidad del bienestar humano, es decir, se crían animales en confinamiento que sólo nacen para servir al hombre, condenados a experimentar infiernos que no caben en la palabra "genocidio", como si:

...en lugar de arrojar a un pueblo a los hornos crematorios y a las cámaras de gas, unos médicos o genetistas (por ejemplo, nazis) hubieran decidido organizar por inseminación artificial la superproducción y la generación asistida de judíos, cíngaros y homosexuales a los que, al ser cada vez más numerosos y estar mejor nutridos, se les habría destinado en un número siempre creciente al mismo infierno, el de la experimentación genética impuesta, el de la exterminación mediante el gas o el fuego. (Derrida, 2008, 42).

En las grandes granjas industriales, en los laboratorios, en los zoológicos, etc., podemos ver el despliegue del control biopolítico contemporáneo a partir de tecnologías altamente desarrolladas. Así como se ha trabajado enormemente sobre la "capitalización" del cuerpo de hombres y mujeres, Nicole Shukin (2009) plantea la idea de "capital animal" para dar cuenta de esa producción, administración y circulación de la vida de los animales en la sociedad capitalista. La capitalización de los cuerpos animales implica que sus vidas se encuentran determinadas estrictamente dentro de las coordenadas de la dominación: los cálculos hechos en torno a la ingesta de nutrientes, los niveles de iluminación, etc., se dirigen a producir "vida" como material para ser consumido, explotado y sacrificado. En otros términos, los cuerpos de los animales son considerados puro objeto de explotación, de sacrificio e instrumentalización: vidas producidas como material disponible, incluidas en el orden socioeconómico neoliberal mediante su sujeción y explotación. La idea del animal como "capital" supone, entonces, una "naturalización" de este ejercicio soberano de sometimiento de la vida.

Ante el panorama mencionado, la filosofía derridiana ofrece elementos para visualizar otro modo de vinculación con lo viviente animal, que no lo considere a éste como vida disponible para ser explotada, dominada y sacrificada. En otros términos, la deconstrucción tiene claras implicancias no sólo para desarticular las relaciones de poder/saber entre humanos y animales, sino también para pensar otros modos de ser-con los vivientes, siempre situados en la apertura a las singularidades humanas y animales.

\section{Límites y posibilidades de una ética de la animalidad}

En los últimos tiempos diversos enfoques científicos y filosóficos han cuestionado el status especial de lo humano, señalando la existencia de lenguaje, herramientas, moralidad, cultura, organización política, etcétera, en distintas especies de animales no-humanos. Esto permite mostrar que aquello atribuido con toda firmeza al hombre, en su pretensión de ser un concepto sin contaminación, preciso y cerrado, se encuentra sujeto a deconstrucciones, desplazamientos y ambivalencias radicales. Por ende, si la respuesta tradicional al vínculo entre lo humano y lo animal establece que, ontológicamente los humanos están separados de los animales de modo taxativo y estos caen "esencialmente" fuera del domino éticopolítico, la cuestión, entonces, es cómo se entiende la ética a partir de la deconstrucción del humanismo. Si lo humano ha sido destituido, ésta ya no puede aparecer asociada a la categoría de naturaleza humana. Sin embargo, la dificultad radica en pensar el lugar de los 
animales en la ética sin re-fundar una comunidad de semejantes a partir de una operación de extensión o inclusión desde el centro hacia el margen. Es decir, debe evitarse instalar una determinada concepción del ser humano en el centro de la reflexión ética para luego extenderla hacia los animales no-humanos.

En el marco de la tradición angloamericana, si bien filósofos como Tom Regan (1983), Peter Singer (1995) o Gary Francione (1996), entre muchos otros, desarrollan planteos morales orientados a problematizar la disponibilidad de la vida animal al servicio de lo humano, reproducen lo que Derrida denomina la estructura carnofalogocéntrica occidental. Lo anterior se deriva de un énfasis excesivo en constructos lógico-racionales característicos de la modernidad, que sitúan en el centro al Hombre racional (también blanco heterosexual y burgués) como ideal normativo, en detrimento de lo instintivo, corporal, sensitivo e irracional. En otros términos, gran parte de esta filosofía moral en torno a los animales se basa en la racionalidad científica dominante para establecer una continuidad entre los seres humanos y los animales con el fin de incluir a éstos en la comunidad moral y política. La sintiencia, es decir, la capacidad de sentir asociada al cerebro y el sistema nervioso, funciona en el animalismo hegemónico como el elemento unificador que delimita de modo exacto quienes pertenecen a la comunidad (el "interior") de aquellos que quedan en el margen ("el exterior"). De ese modo, dentro de la mayoría de estos enfoques, los animales se incluyen dentro del alcance de las consideraciones éticas en la medida en que son como los humanos, de modo éticamente relevante, mientras que otros seres desemejantes se dejan fuera del ámbito de la consideración. La conclusión resultante de estas estrategias culmina, en la mayoría de los casos, en la necesidad racional de atribuirles "derechos" a los animales en tanto "personas".

El hombre se presenta, entonces, como un sujeto agente capaz de accionar moralmente, que puede decidir racional y soberanamente sobre quiénes forman parte de la comunidad ético-política, lo cual ubica al otro animal bajo la propiedad y el poder del sujeto humano, redibujando las mismas líneas de exclusión. Lo que a su vez da por supuesto que la subordinación de los seres no humanos puede ser cuestionada y superada por medio de las mismas instituciones del sistema moderno/colonial. Asimismo, los desarrollos tradicionales en torno a la ética animal operan según una lógica dicotómica (animal y vegetal, respuesta y reacción, sintiente y no-sintiente, etc.) e identitaria. Nociones que transforma en fundamentos al convertirlas en principios determinantes del pensamiento y de la acción, a modo de imperativo, de télos del obrar. Pero, como ha puesto de relieve la crítica de Nietzsche a la metafísica tradicional, toda dicotomía da cuenta de una violenta jerarquía, donde uno de los polos ocupa una posición superior y el otro es marginado. Cuando se elige uno de los términos se elige un centro, una forma de ordenamiento, una forma de jerarquización. Es decir, el establecimiento de una objetividad fuera del tiempo opaca las diversidades e invisibiliza las alteridades no totalizables ni homogeneizables. De ahí el surgimiento de los estudios feministas, culturales, ambientales, pacifistas, queer, etc., enfocados en resolver asuntos construidos como problemáticos para "sujetos" específicos. Si los conceptos de Hombre/animal y Sujeto/objeto han probado ser absolutamente opresores en la práctica ¿cómo el movimiento de liberación animal puede seguir apelando a dichas ideas? Ello tiene por resultado, como señala Calarco (2008), que el activismo por los derechos de los animales adopte el lenguaje y la estrategias de la identidad, un 
camino que aísla aún más a la liberación animal de otras arenas del activismo político (como el ecofeminismo, por ejemplo), que buscan, de forma similar, subvertir determinadas estructuras de opresión.

En el seminario La bête et le souverain se patentiza de qué modo los conceptos de sujeto, derecho, soberanía, e incluso de comunidad, se definieron desde el sacrificio animal. Derrida utiliza el término carno-falogocentrismo para dar cuenta de una maquinaria sacrificial de naturalización de la muerte de los otros animales en una ontología fundamentalmente masculina. Esta violencia política supone una valoración absoluta de la Razón, sin la cual no es posible ser parte de la comunidad política, característica que es precisamente considerada como una propiedad del Hombre en tanto principal referente de la Norma, de la Ley y del Logos (Braidotti, 2005, 102). En otros términos, a partir de los términos carno-falogocentrismo y virilidad carnívora (2005) el autor señala cómo la autoridad política en Occidente se encarna en el hombre-varón que se piensa como racional y que expresa su racionalidad a través del sacrificio de la carne. En este sentido, estas nociones muestran que el modo de ser humano aparece, al menos en buena parte de la tradición occidental, en la figura masculina del amo, del jefe, del padre de familia o del marido, y que por esa posición de poder se autoriza el control, la regulación y el sacrificio de los así constituidos como Otros.

Consecuentemente, en la medida en que la idea de los "derechos de los animales" sigue estando asociada estructuralmente a la subjetividad moderna, re/produce el privilegio occidental del hombre-viril-blanco-heterosexual-burgués, el cual ha sido "la palanca misma de la peor violencia llevada respecto de los vivientes no humanos" (Derrida \& Roudinesco, 2009, 76). El pensador busca de esa manera hacernos comprender que la lógica sacrificial que determina nuestras relaciones con los vivientes, no será resistida de modo radical si no nos interrogamos por los límites de nuestra inteligibilidad presente: para socavar la violencia del humanismo es necesaria una deconstrucción de los cimientos de nuestra ontología y un cuestionamiento radical de los presupuestos de la ética, el derecho y la política tal como han sido pensados históricamente.

Si queremos hablar de injusticia, de violencia o de falta de respeto hacia lo que todavía llamamos de manera confusa el animal -nunca esta cuestión había sido tan actual, (e incluyo en la misma, a título de la desconstrucción, todo un conjunto de cuestiones sobre el carno-falogocentrismo)-, hay que reconsiderar la totalidad de la axiomática metafísico-antropocéntrica que domina en Occidente el pensamiento de lo justo y de lo injusto. (Derrida, 1997, 44)

Es decir, antes que buscar un criterio para determinar la considerabilidad moral, es menester preguntar por qué se ha llegado a afirmar que esto o aquello tiene dignidad inherente y esto o aquello no, cómo podría ser diferente, de qué manera se configuró una sensibilidad y un comportamiento o movimiento y cómo transformarlo. Es la lógica sacrificial que subyace a nuestras prácticas y modos de pensar dominantes, lo que debe ser cuestionado para lograr un cambio efectivo en las condiciones de vida de los animales humanos y no humanos.

Una de las claves del seminario La bête et le souverain es la pregunta por el pasaje del "quién" al "qué", donde el "quien" indica la figura del soberano, del sujeto o el "ipse". 
Debido a que tradicionalmente se considera que los animales sólo reaccionan y no responden, se asume que no pueden asumir la figura del quien. Si los animales no puede ser un "quien", son entonces considerados en términos de "qué", es decir, como un objeto sacrificable. Dado que la figura del "quien" está vinculada con la incondicionalidad de la soberanía en su carácter fálico y sacrificial, el tránsito derridiano se dirige hacia la idea de una incondicionalidad sin soberanía, donde ese "que" es pensado como otro. De este modo, no se busca conferirle al animal la figura del "quien" para así sostener una especie de identidad fundamental (la subjetividad) compartida por todos los animales. El desafío del filósofo consiste en pensar el pasaje como punto tensional, como "entre": punto que nos impide detenernos en una identidad al retenernos en el inquietante espacio que se abre entre el quién y el qué. En palabras derridianas, la cuestión es:

...pensar una incondicionalidad (ya se trate de la libertad, del don, del perdón, de la justicia, de la hospitalidad) sin soberanía indivisible. Es más que difícil, es aporético, desde el momento que la soberanía se ha considerado siempre indivisible, por consiguiente, absoluta e incondicional. (2010, 354).

En efecto, la deconstrucción de la soberanía habilita otras posibilidades que no se detienen en lo que el derecho o la política son en el presente, sino que convocan un derecho, una política, una ética y una comunidad por venir. Por ello, si el sujeto soberano somete a los animales rechazándolos fuera de la comunidad política, ello lleva a la necesidad de cuestionar la soberanía en nombre de la incondicionalidad, para así pensar la ética y la política desde la diferencia y la alteridad animal. Es desde la deconstrucción de la subjetividad moderna, en su carácter fálico y sacrificial, que tal vez sea posible pensar la apertura comunitaria a las singularidades vivientes, allí donde se renuncia a la lógica sacrificial que privilegia determinadas vidas por sobre otras. Dado que la dicotomía humano-animal ha sido un modo privilegiado para legitimar la explotación y la violencia de esos Otros que no responden a la ficción normativa de lo Humano, su desmantelamiento implicaría socavar uno de los modos en virtud del cual se llevó a cabo dicha subordinación. La cuestión de lo animal se presenta, según esta perspectiva, como una lectura de lo político que cuestiona radicalmente la noción eurocéntrica de Sujeto y las instituciones moderno-coloniales.

\section{La comunidad en el abismo de los vivientes}

El análisis crítico de "lo humano" que encontramos en pensadores como Rosi Braidotti (2005), Jacques Derrida (2008, 2010), Gilles Deleuze y Félix Guattari (2002), Giorgio Agamben (2002), entre otros, es una de las principales tendencias dentro de la filosofía post-nietzscheana. Estos autores se han dedicado a criticar cierto modo sustancialista de comprender la subjetividad, para proponer una manera histórica y procesal de pensar su constitución, emprendiendo un desmontaje de las definiciones tradicionales de lo humano y lo animal. Desde este enfoque, "hombre" y "animal" no son nombres para describir a seres previamente existentes a las categorías y a las políticas que pretenden representarlos, sino que son producidos por esos mismos esquemas categoriales de acuerdo a determinadas relaciones de poder y dominación. Si seguimos la línea de pensamiento abierta por estos 
filósofos, entonces tenemos que repensar de manera fundamental el carácter históricamente determinado de nuestro modo de configuración de lo humano. Y si la cuestión de "quién" se considera propiamente ser humano permanece siempre abierta a discusión, ya no es posible tener seguridad sobre cómo podría ser pensada nuestra relación con los vivientes animales. En otras palabras, la resistencia animal demanda la búsqueda de lugares de enunciación situados y alternativos, desde los cuales asentar otros modos de concebirnos a nos-otros y a los otros, así como la creación de nuevos lenguajes, conceptos y ficciones. De allí que, para pensar el desplazamiento del antropocentrismo, sea necesario imaginar otros modos de concebir la vida animal y las relaciones éticas entre las singularidades vivientes.

Nietzsche con su crítica a la filosofía monótono-teísta, así como Derrida y su propuesta deconstructiva del carnofalogocentrismo, permiten pensar otros modos de la subjetividad y la animalidad como posibilidad ético-política para otras filosofías de lo viviente. El descentramiento de la subjetividad, de su pretensión apropiadora, es pensado en Así habló Zaratustra bajo la figura del Übermensch, abriendo un lugar para lo que el humanismo antropocéntrico ha sometido: "Yo amo a quienes no saben vivir de otro modo que hundiéndose en su ocaso, pues ellos son los que pasan al otro lado.”(Nietzsche, 1994, 36) La figura de "hundirse en el ocaso" abandona toda presencia de la subjetividad apropiadora, la búsqueda de todo sentido asegurado e implosiona la idea de identidad para pensar la multiplicidad que somos. Si el sujeto moderno es la figura del propietario-poseedor, lo propio del Übermensch es el no-dominio, es decir, enfrentarse a lo que acontece sin intentos de apropiación. El sujeto aparece como el entre provisorio que se sostiene en la trama del devenir, desbaratando toda dicotomía asegurada.

Señala Nietzsche: "No se puede preguntar ¿quién interpreta? Sino que el interpretar mismo tiene existencia como forma de la voluntad de poder (pero no como un ser, sino como un proceso, como un devenir)" (Citado por Sánchez Meca, 1989, 133) cuestionando, de este modo, la idea de sujeto agente y productor de la modernidad. El hombre deja de aparecer como el lugar de determinación de la existencia y se muestra como un resultado. Ubicarse en el lugar de producto deconstruye la actitud tradicional del hombre como sujeto representativo, racional y consciente de sí, lo cual permite otras posibilidades de ser-en-elmundo con lo viviente. Nos constituimos en la tensión y el devenir, transitando umbrales.

Tras Nietzsche, la constitución de la(s) subjetividad(es) en el pensamiento derrideano implica una puesta en abismo de la noción moderna de hombre autotransparente, autónomo, seguro de sí y una ruptura con respecto a toda idea de la identidad como aseguramiento de la propia mismidad. La deconstrucción, según propone Derrida, consiste en "ligar una afirmación (sobre todo política), si la hay, a la experiencia de lo imposible, que no puede ser sino una experiencia radical del puede ser, del "tal vez" (1998c, 48). Es decir, al asumir la imposibilidad de aplicar una fórmula o una regla válida universalmente, la deconstrucción señala la necesidad de dar una respuesta singular, en cada contexto, afirmando el ries $\neg$ go de una tarea siempre incumplida:

Puedo entonces aceptar una alianza momentánea, prudente, al mismo tiempo que subrayo sus límites, haciéndolos tan explícitos e inteligibles como sea posible [...] La responsabilidad política ante situaciones siempre complejas, contradictorias y sobredeterminadas, es tratar de calcular el espacio el tiempo y el límite de la alianza. (Derrida, 2009: 31). 
Por lo tanto, antes de buscar determinar una nueva línea de demarcación, es preciso examinar lo siguiente: ¿Qué sucede si se pone en tela de juicio esa razón aseguradora y calculadora que decide sobre la inclusión/exclusión dentro de la comunidad moral? ¿Cuáles serían las implicaciones para la ética animal si se abandona la búsqueda de fronteras sin contaminación? Frente a esa búsqueda de un elemento unificador, la filosofía derridiana ha mostrado que el esfuerzo por determinar el interior y el exterior de la comunidad es uno de los gestos fundacionales más problemáticos en la tradición metafísica occidental, porque suponen una reducción a la economía de lo mismo de la diferencia del Otro. En una apuesta por una comunidad del respeto a la diferencia, la deconstrucción señala la imposibilidad de establecer una propiedad que delimite el espacio de lo común. Ese supuesto espacio de lo propio está desde un comienzo siendo asediado por lo otro de él, desde siempre en deconstrucción por esa presencia alter-ante. Por ello, la ética tiene lugar como radical cuestionamiento del sujeto, interpela al lugar de una alteridad inapropiable e irreductible a lo mismo. En palabras derridianas:

Lo "incognoscible" (...) es el comienzo de la ética, de la Ley, y no de lo humano. Mientras hay algo reconocible, y semejante, la ética dormita. Duerme un sueño dogmático (...) Lo "incognoscible" es el despertar. Es lo que nos despierta, es la experiencia de la vigilia misma. Lo "incognoscible", por lo tanto, lo desemejante. (2010, 139).

La pregunta por la identidad siempre constriñe a un ámbito de poder que el "yo" puede ejercer respecto al otro. Por ello, si la ética compromete mi responsabilidad con lo otro incognoscible, entonces hay un desborde y una excedencia con respecto a la lógica del cálculo y del aseguramiento. El otro incognoscible irrumpe, no puede colocarse bajo categorías de semejanza porque tiene el carácter de lo Unheimliche, es decir, está más allá de todo poder de cálculo y reconocimiento. De allí que no sea posible ni deseable realizar una operación de "inclusión" para inscribir a lo viviente animal en el dominio ético-político. Antes bien, la filosofía derridiana permite pensar una "ética animal de la diferencia" como resistencia al cierre totalizador del humanismo que establece un afuera y un adentro de la comunidad, a partir de lo común y de lo semejante. Si Derrida piensa un modo del encuentro con el otro y la comunidad sobre la base de la otredad, los animales constituyen la posibilidad de quiebre de la relación entre totalidades y el lazo comunitario. Por ello, una ética animal de la diferencia estaría alejada de toda síntesis reapropiadora según la reproducción del horizonte de lo posible; por el contrario, se anunciaría desde la medida de lo imposible, que rompe toda forma de totalidad y no anuncia nada más que la venida de aquello que desborda cualquier horizonte presente.

A partir del neologismo francés animot Derrida deja oír una pluralidad (animaux) silenciada en el término singular ("animal"), que no es "ni una especie, ni un género, ni un individuo, es la irreductible multiplicidad viviente de los mortales" (2008). Lo cual supone un modo de aproximarse a la cuestión animal, tanto desde el punto de vista metafísico como desde una perspectiva ético-política, que se distancia radialmente de la lógica de lo común que clausura la apertura de la comunidad. Es decir, si en la tradición angloamericana la pregunta ética por los animales se encuentra inextricablemente ligada a una concepción 
totalizante de la subjetividad y de la comunidad, Derrida rompe con el ideal moderno que da sede a un relato homogéneo como garantía de la igualdad comunitaria. En la noción de animot lo que está en juego es un "vivir juntos" de humanos y animales, que borra toda excepcionalidad humana y trasciende el mero esquema de equivalencias entre unos y otros.

En la obra Políticas de la amistad (1998a) Derrida realiza una lectura de las determinaciones fraternalistas en la constitución de cierta concepción de lo político, señalando la predominancia de un esquema familiar que confunde la figura del amigo con la del hermano. En compañía de Gabriela Balcarce, podemos sostener que la fraternidad está ligada fundamentalmente a un parentesco originario: la pertenencia a la comunidad del Padre (Balcarce, 2010). En contraste con este esquema, el filósofo retoma la idea paradójica de la amistad elaborada por Nietzsche (1998a) afirmando que el amigo constituye la figura inapropiable de un otro radical que me precede e interpela. Esta interpretación de la amistad, "dislocaría por anticipado toda ipseidad, arruinaría por anticipado justo aquello que ella hace posible, el narcisismo y la auto-ejemplaridad" (Derrida, 1998a, 42). Ello implica una ruptura con las filosofías morales que fundan la acción ética con el otro pensándolo en términos de un semejante y que conciben el vínculo comunitario desde lo familiar.

Frente a la comunidad de lo mismo, la propuesta derridiana se articula en términos de un ser-en-común que es la nada-en-común, es decir, la nada de propiedad, la ausencia de pertenencia. La comunidad-que-somos es, entonces, la ausencia de un espacio de lo propio y de rasgos de identidad. Esa ruptura de la relación entre el lazo comunitario y las ideas de propiedad-pertenencia permite abrir hacia una política no sacrificial, ya sea en términos de sangre, de filiación, de raza, de especie, etc. En este sentido, si el otro animal opera como el afuera, a partir del cual se delimita el espacio humano de organización de lo común, los animales constituyen el principio de ruina de toda comunidad política, emergen como el desfasaje que produce el quiebre de aquel horizonte humanista.

En Autoinmunidad: Suicidios reales y simbólicos Derrida establece que: "La hospitalidad pura e incondicional, la hospitalidad misma se abre, está de antemano abierta, a cualquiera que no sea esperado ni esté invitado, a cualquiera que llegue como visitor absolutamente extraño, no identificable e imprevisible al llegar, un enteramente otro. Llamemos a esta hospitalidad de visitación y no de invitación" (2004, 187). La hospitalidad, tal como la concibe Derrida, busca romper con aquel esquema que la asocia a un sujeto que, supuestamente dueño de su propia casa, determina sobre la venida del otro a partir de ciertas normas, según una "lógica de la invitación". Por otra parte "una hospitalidad incondicional es, ciertamente, prácticamente imposible de vivir; uno no puede en todo caso, por definición, organizarla." Por lo tanto, Derrida concluye: "ese concepto de la hospitalidad pura no puede tener ningún estatus jurídico o político." Pero, al mismo tiempo, sin ella no podríamos "ni siquiera determinar ninguna norma de la hospitalidad condicional (con sus ritos, su estatus jurídico, sus normas, sus convenciones nacionales o internacionales)" (2004, 187). En este sentido, "la hospitalidad incondicional, que no es aún ni Jurídica ni política, es sin embargo la condición de lo político y de lo jurídico." No obstante, como la justicia, sólo puede tener lugar a través de ejemplos concretos, pragmáticos de iteración, instancias que son selectivas y excluyentes, y por lo tanto "condicionales": "yo no puedo abrir la puerta, exponerme a la llegada del otro y darle cualquier cosa sin hacer esta hospitalidad efectiva, sin dar concretamente alguna cosa determinada" (2004, 188). En otros términos: para que la hospitalidad tenga espacio y efectividad ha de ser 
condicionada, pero ello supone un acto de selección y exclusión, que por su contingencia e historicidad, permanecerá abierto hacia el porvenir y a todo otro, quienquiera que sea.

Desde esta perspectiva, es posible pensar una ética que rompa con la lógica del intercambio y la exigencia de reciprocidad en virtud del reconocimiento de la igualdad. La imposibilidad de anticipación del otro supone la ruptura de cualquier horizonte de anticipación, así como también la violencia de su advenimiento. Y dado que el otro arribante puede ser tanto un amigo como un enemigo, la ética se mueve siempre en el ámbito de la imprecisión. Así, si tradicionalmente el acto moral ha sido pensado en términos de un sujeto agente que realiza la acción, no poder determinar nada con respecto al otro implica una declinación del modo de ser del sujeto moderno, bajo la idea de la pasividad en la impotencia de dejar ser.

Derrida, retomando a Lévinas, recuerda que la ética aparece con el "después de usted" (2010, 125), es decir, con el respeto al otro en tanto tal. Ello quiere decir que, si bien el sujeto se ha ubicado en el lugar del dominio, del fundamento, se encuentra desde siempre deconstruido por la amenaza del otro. Pero, si la ética aparece con el respeto que le debemos al otro en tanto otro, quienquiera que sea, irreductible e inanticipable, y si antes de cualquier identificación ya tenemos responsabilidad con el otro que es el primer llegado, entonces no es posible establecer el punto exacto que demarca la comunidad de iguales (quiénes deben tener consideración y quiénes no), y sobre el cual debemos levantar nuestro edificio del juicio. Por ende, en lugar de tratar de calcular un criterio de considerabilidad moral definitivo, podríamos afirmar la exposición sin límites al otro, al que llega, al acontecimiento. Lo cual supone que los límites de la responsabilidad ética sean problemáticos y revisables.

Dado que las afirmaciones de Derrida no pueden ubicarse en un discurso programático de lo político, cabe la pregunta sobre cómo es posible enfrentar desde este enfoque las instituciones y los marcos socioeconómicos contra el cual luchan los teóricos y activistas de animales. En otros términos: ¿cuál es el potencial transformador que posee la deconstrucción para radicalizar las políticas de resistencia en torno a lo animal? Mientras la tradición angloamericana busca conceder a los animales igualdad de acceso a la comunidad ética y política, creemos que la potencia de la deconstrucción radica en su llamado a explorar nuevas formas de concebir las relaciones entre humanos y animales. Esto es, si dicha tradición, al intentar ampliar la comunidad moral, deja sin cuestionar la ficción normativa llamada Hombre y por ende, la lógica sacrificial que subyace a nuestras prácticas dominantes; la deconstrucción patentiza el carácter político (y por tanto, contingente y no-originario) de categorías pretendidamente autofundadas como lo humano y lo animal. Emprender la deconstrucción de dichos conceptos supone mostrar su condición histórica. Supone situarlos en una trama de sentidos y constricciones políticas, culturales y discursivas que patentizan en su carácter de producto y por ende, emergen como cuestionables, discutibles y modificables.

Si nos constituimos en la tensión y el devenir, no es necesaria una ética animal que, desde una lógica de homogeneización, considere al animal como un otro-igual. No se trata de reconocer a los animales como seres sintientes a partir de argumentos científicos, sino de asumir la comunidad por venir en la apertura abismal de las singularidades, tanto humanas como no-humanas. Si la ética se caracteriza por el riesgo y la imprecisión, lejos 
de asegurarnos en el conformismo de un proyecto de reformas, quizás sea deseable apostar por el desarrollo de estrategias postidentitarias de subversión y resistencia animal desde un lugar esquivo, plural y en continua deconstrucción. En este sentido, la búsqueda de otros modos de pensar nuestras relaciones con los vivientes animales no puede obliterar el carácter arbitrario de toda construcción de lo común, que jamás podrá asentarse sobre un fondo sustancial. Es desde el fondo abismal de toda configuración del ser-en-común y desde la aceptación del carácter provisorio inherente al mismo, que es posible pensar nuevas configuraciones hospitalarias con los otros animales.

Tal vez el "después de usted", retomado por Derrida, entraña una política de las hospitalidad en todos los casos concebida como experiencia colectiva, donde la ruptura de los bordes siempre permeables de la "primera persona del singular" transfigure los momentos de resistencia en efectivas subversiones. En esa transición parece jugarse la posibilidad de encarar un proceso de transformación, corrimiento y desplazamiento de la lógica antropocéntrica, que no sólo asuma ontológicamente la crisis de lo humano, sino que afronte las consecuencias ético-políticas de asumir dicha declinación. Es decir, que ofrezca posibilidades para contribuir, al menos parcialmente, a desbaratar las principales prácticas del carnofalogocentrismo. Desde esta perspectiva, no resulta deseable ni posible formular grandes programas de acción o una regla válida universalmente. Si bien estratégicamente es necesario hablar de "derechos", no se debe perder de vista las lógicas de sacrifico, explotación y sumisión del régimen carnofalogocéntrico. En todo caso, es posible apostar por diferentes prácticas que, desde los márgenes, desbaraten la supuesta superioridad humana, blanca y masculina. En otros términos, antes que "dar voz" a los animales y personificarlos en diversos escenarios (como declaraciones, normatividades y políticas públicas), el desafío que nos propone la deconstrucción es pensar discursos y prácticas situadas y heterogéneas, que contribuyan a liberar las corporalidades animales a otras posibilidades, para que emerjan como aquellos cuerpos múltiples y potentes, cuya existencia misma desborda nuestras ficciones identitarias y principios de inteligibilidad. Prácticas y discursos que, desafiando las condiciones éticas y políticas de legitimidad de nuestra actualidad, se encaminen a la escucha de la demanda de justicia de los otros animales y del animal que somos.

Ante el desmoronamiento de la dicotomía entre lo humano y lo no-humano el desafío será imaginar modos de vida que desplacen radicalmente al Hombre como centro de la reflexión ética y política. Reducir las posibilidades de ser, experimentar y hacer a cierta ficción normativa de lo humano es negar la potencia creativa de la vida. Así pues, en lugar de apelar a un elemento sustancial para legitimar nuestra actividad política, podemos intentar ubicarnos "más allá del bien y del mal", es decir, más allá de los modos dicotómicos y normalizantes que han organizado mundos y modos de vida demasiado humanos. Quizás así seremos capaces de crear territorios existenciales alternativos, nuevos (y provisorios) mundos que, en lugar de sojuzgar e invisibilizar la diversidad de los cuerpos, afirmen la pluralidad y la multiplicidad de los vivientes.

\section{Bibliografía}

Adams, C. J. (2010), The Sexual Politics of Meat: A Feminist-Vegetarian Critical Theory, Twentieth Anniversary Edition, New York \& London: Continuum. 
Agamben, G. (2002), Lo abierto, el hombre y el animal. Buenos Aires: Adriana Hidalgo editora.

Balcarce, G. (2010), "Pensamientos de la hospitalidad. Herencias e inspiración”, Ágora. Papeles de Filosofía, vol. 30-31, Universidad de Santiago de Compostela, 2010, pp. 173-192.

Balibar, F.; Hoquet, T., (2009), "Le partage du monde entre les animaux", en Libérer les animaux? Critique 747-748, Paris: Éditions du Minuit, 2009.

Benjamin, A. (2010), Of Jews and Animals, Edinburgh: Edinburgh University Press, 2010.

Braidotti, R. (2005), Metamorfosis hacia una teoría materialista del devenir. Madrid: Ediciones Akal.

Calarco, M. (2008),Zoographies. The Question of the Animal from Heidegger to Derrida. New York: Columbia University Press.

Cragnolini, M. B. (2000) "Filosofía nietzscheana de la tensión. La resistencia del pensar" en Contrastes. Revista Interdisciplinar de Filosofía, Vol. 5, Sección de Filosofía, Universidad de Málaga, pp. 225-240.

Cragnolini, M. B. (2012), "Virilidad carnívora: el ejercicio de la autoridad sojuzgante frente a lo viviente" Revista Científica de UCES; Buenos Aires, vol. 16, pp. 23-29.

De Fontenay, E., (1998), Le silence des bêtes, La philosophie á l'épreuve de l'animalité, Paris, Fayard.

Deleuze, G, Guattari, F. (2002), Mil mesetas, capitalismo y esquizofrenia. Valencia: Pretextos

Derrida, J. (1997) Fuerza de ley. El «Fundamento místico de la autoridad». Trad. Adolfo Barberá y Patricio Peñalver, Madrid, Tecnos

Derrida, J. (1998a) Políticas de la amistad. Seguido de El oído de Heidegger. Trad. P. Peñalver y P. Vidarte. Madrid

Derrida, J. (1998b) Adiós a Emmanuel Lévinas. Palabra de acogida, trad. Julián Santos Guerrero, Madrid, Trotta

Derrida, J. (1998c) Espectros de Marx El estado de la deuda, el trabajo del duelo y la nueva internacional, trad. José Miguel Alarcón y Cristina De Peretti, Madrid, Trotta.

Derrida, J. (2000), La hospitalidad, trad. Mirta Segoviano, Buenos Aires, Ediciones de la Flor,

Derrida, J. (2003), "Violencia y metafísica" en La escritura y la diferencia, Trad. P. Peñalver, Madrid, Editora Nacional.

Derrida, J. (2004), La filosofía en una época de terror. Diálogos con Jürgen Habermas y Jacques Derrida, Trad. de J.J. Botero y L.E. Hoyos, Buenos Aires, Taurus.

Derrida, J. (2005), "Hay que comer, o el cálculo del sujeto" (entrevista con J-L Nancy), trad. V. Gallo y N. Billi en Pensamiento de los confines, Nro 17, dic.

Derrida, J. (2008), El animal que luego estoy si(gui)endo, Madrid, Editorial Trotta.

Derrida, J. (2010), Seminario La bestia y el soberano, Vol I trad. de C. de Peretti y D. Rocha, Manantial, Buenos Aires.

Derrida J. \& Roudinesco É. (2009), “Violencias contra los animales” en: Y mañana qué, trad. V. Goldstein, F.C.E., Buenos Aires.

Francione, G. (1996), Rain without Thunder: The Ideology of the Animal Rights Movement. Philadelphia: Temple University Press. 
Lawlor, L. (2007), This Is Not Sufficient: An Essay on Animality and Human Nature in Derrida, New York: Columbia University Press.

Nietzsche, F. (1994), Así habló Zaratustra, trad. de Andrés Sánchez Pascual, Madrid, Alianza.

Nietzsche, F. (1997), Crepúsculo de los ídolos, Trad. A. Sánchez Pascual, Madrid, Alianza.

Regan, T. (1983) [2008], 'The case for animal rights', in S. Armstrong \& R. Botzler (eds) The Animal Ethics Reader (2nd edition), Routledge, London.

Regan, T. (2001), Defending Animal Rights, Ilinois, University of Illinois Press.

Sánchez Meca, D. (1989), En torno al superhombre, Ed. Anthropos, Madrid 1989.

Shukin, N. (2009), Animal Capital. Rendering Life in biopolitical Times, MinneapolisLondon, University of Minnesota Press.

Singer, P. (1995), Animal Liberation, 2nd ed., London: Pimlico.

Wolfe, C. (2003), Animal Rites. American Culture, the Discourse of Species and Posthumanist Theory. Chicago: University of Chicago Press. 
